\title{
PROTRUSIONS OF THE LUMBAR INTERVERTEBRAL DISCS *
}

\author{
A Clinical Review Based on Five Hundred Cases \\ Treated by Excision of the Protrusion
}

\author{
John E. A. O'Connell, London, England
}

From the Department of Neurosurgery, St Bartholomew's Hospital, London

Though lumbago and sciatica carry little threat to life, they may interfere greatly with living. Their frequency and their annual toll of suffering and disability have been a constant stimulus to investigation. The discovery by Mixter and Barr in 1934 that an intraspinal protrusion of a lumbar intervertebral disc was sometimes the cause of these troubles was outstandingly important, for it not only provided a rational basis for treatment but also led to the careful investigation in hospital of large groups of these patients, with a further growth in knowledge. That lumbago and pain in the lower limb are essentially subjective disturbances makes for certain difficulties in reviewing a series of cases, particularly in assessing the results of treatment. When the present investigation was planned it was considered that the difficulty might be lessened if the case records were made by the individual who would subsequently review them. In every case, therefore, at least one pre-operative examination and a number of post-operative examinations were made by the author. Further, all cases in the series were operated upon by him - except a few in which he assisted his registrar. The operative findings were immediately recorded. These constitute the records which have been analysed, and they belong to 500 cases of proven lumbar intervertebral disc protrusion operated upon between January 1938 and May 1948 at St Bartholomew's Hospital. The purpose of the investigation has been: firstly, to crystallize our experience with cases of low back and lower limb pain; and secondly, to determine the results of excision of intervertebral disc protrusions in a large group of patients observed for an adequate period after operation.

\section{SEX AND AGE INCIDENCE}

There were 330 males (66 per cent) and 170 females ( 34 per cent). That males were affected twice as often as females is doubtless related to the heavier nature of their work. The age distribution is shown in Figure 1. The youngest patient was aged sixteen years and the oldest fifty-eight years. Most were in the fourth decade and almost three-quarters were between the ages of twenty-one and forty.

\section{PATHOLOGY}

It is necessary first to consider briefly how lumbar intervertebral disc protrusions produce their characteristic clinical picture. The posterior common ligament and the annulus fibrosus of the intervertebral disc are supplied with sensory nerve fibres. Low back pain may be the consequence of: a tear of either structure, as in other sprains; stretching of the torn ligaments by the protruding nucleus pulposus, aggravated by postures and movements which increase the considerable pressure within it; and possibly the abnormal stresses developed in the muscles, ligaments and synovial [diarthrodial] joints of the lumbar spine in consequence of the injury to one of the large symphysial joints between the vertebral bodies. The lower

* A Hunterian lecture given at the Royal College of Surgeons of England on February 16, 1950. 


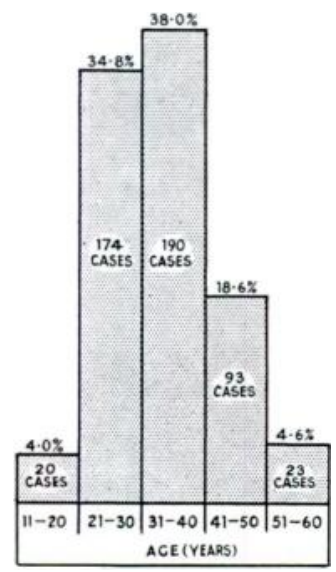

FIG. 1

Histogram showing the age distribution among 500 patients operated upon for protrusions of intervertebral discs.

limb symptoms and signs are caused by compression and stretching of the nerves of the cauda equina, or sudden injury of them, by the protruded disc. Three circumstances may obtain: 1) If a large mass of disc tissue enters and fills the spinal canal all the contained nerve roots will be compressed (Fig. 2). 2) In the more usual type of protrusion a relatively small mass of disc tissue enters the spinal canal and becomes intimately related to one anterior and one posterior spinal nerve root between their point of emergence from the dural theca and their entrance into an intervertebral foramen. In this part of their course, where the two roots together constitute an extradural intraspinal nerve they are invested by a dural sheath. Unlike the dural theca, which with its contained nerve roots is readily displaced by a protruded disc, the extradural nerve with its strong dural sheath is relatively taut, and a small protrusion-or even strong adhesions between this nerve and the intervertebral disc-

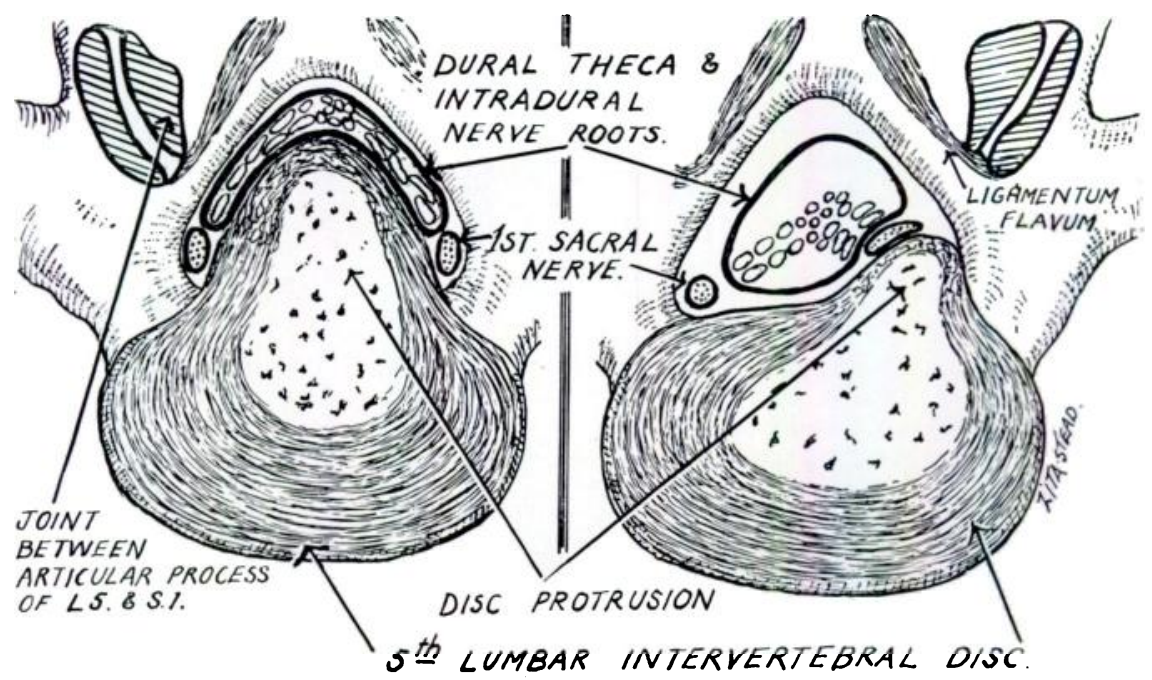

FIG. 2

Diagrams of sections through the lumbo-sacral intervertebral disc. In the drawing on the left a large central disc protrusion is shown. That on the right shows the more common lateral protrusion with the first sacral nerve stretched over it.

VOL. 33 B, NO. 1, FEBRUARY 1951 
may sufficiently increase the tension within it to cause pain. Even if the protrusion is large enough to displace the nerve backwards against the vertebral lamina it is believed that tension remains the important factor, since, without it, the nerve would be displaced like the theca and its contents. 3) Sometimes the displacement of a large mass of disc tissue is sudden: the roots of the cauda equina suffer an acute injury and the clinical picture of a severe lesion of the lower lumbar and sacral roots is at once established. Review of the operative findings in 350 cases of this series suggests that the clinical picture was caused by compression alone in 1 per cent, by tension alone in 31 per cent, by a combination of stretching and compression in 66 per cent, and by sudden injury to the cauda equina in 2 per cent.

TABLE I

Etiological Factors in 500 Cases of Intervertebral Disc Protrusion Treated by Operation

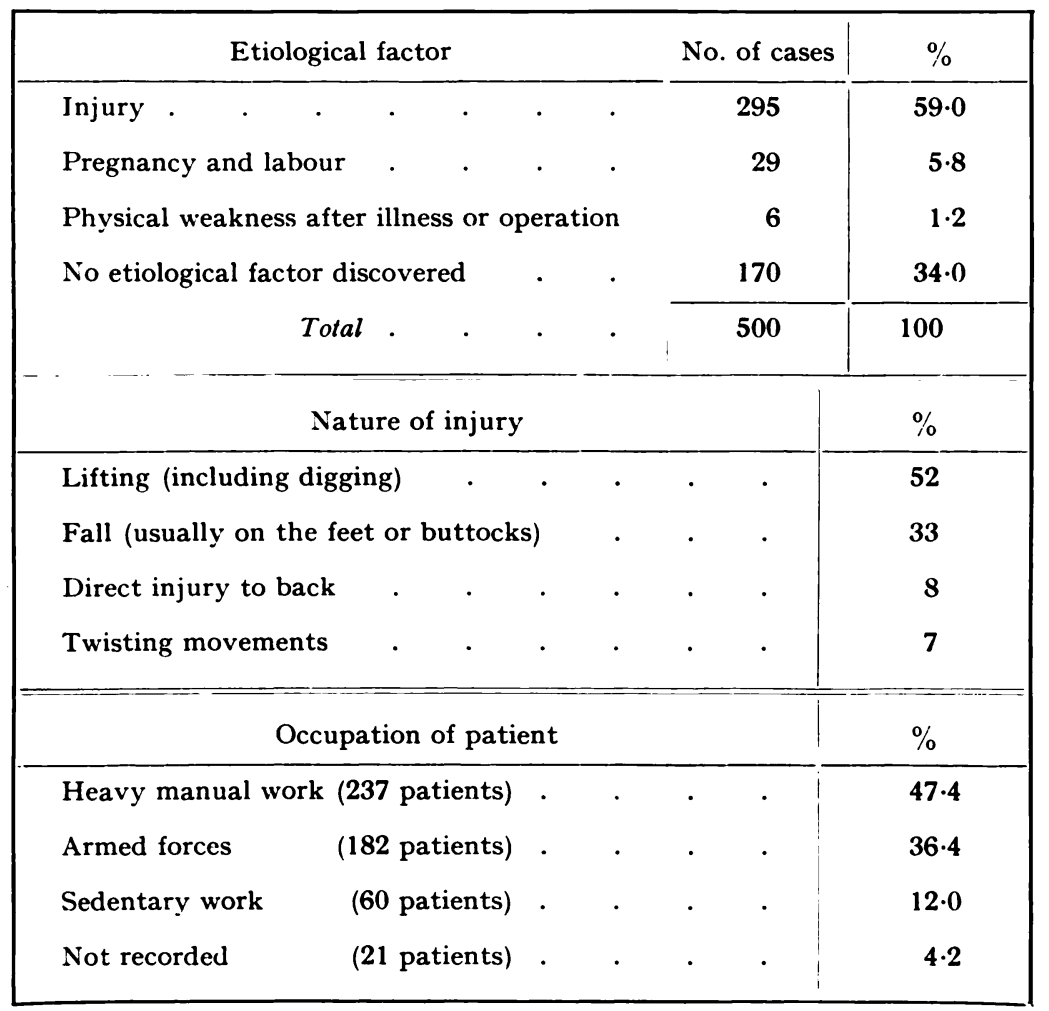

\section{CAUSATIVE OR PREDISPOSING FACTORS}

The factors thought to cause or contribute to the lumbar disc protrusion are analysed in Table I. The importance of a definite and remembered injury is clear. Pregnancy and labour were responsible factors in 17 per cent of the female patients. It has been suggested ( $O$ 'Connell 1944) that the corpus luteum hormone, which causes relaxation of the ligaments surrounding the pelvic joints, might also affect the lumbar intervertebral joints, so that they may become more vulnerable to the ordinary physical stresses of life as well as to the extraordinary stresses associated with child-bearing. The development of symptoms immediately after recovery from anaesthesia or during convalescence suggests that the reduced muscular tone present at such times may predispose to intervertebral disc injury. The type of causative injury was determined from the records of 123 patients from whom exact information was obtained: 
in 85 per cent the injury was sustained either in lifting some heavy weight or in falling. The occupations of 84 per cent of the patients caused physical stress. Anyone unaccustomed to such stresses was perhaps more likely to sustain intervertebral disc injury, and the high proportion of Service patients in the series may perhaps be so explained.

\section{GLINIGAL FEATURES}

The distribution of pain is analysed in Table II. In most patients low back pain and lower limb pain were present together. In 13 per cent pain occurred in the lower limb alone: in only one patient was it confined to the lumbar region. This does not imply that lumbar disc protrusions seldom cause low back pain without sciatica: on the contrary many patients with sciatica in whom a protrusion is ultimately found at operation have a history of one or more previous attacks of localised low back pain. The correct inference from our experience

TABLE II

Distribution of Pain in 500 Cases of Intervertebral Disc Protrusion Treated by Operation

\begin{tabular}{|c|c|c|c|c|c|c|c|}
\hline \multicolumn{6}{|c|}{ Distribution } & No. of cases & $\%$ \\
\hline \multicolumn{3}{|c|}{ Lumbar spine and lower limb } & . & . & • & 434 & $86 \cdot 8$ \\
\hline \multicolumn{2}{|c|}{ Lower limb only } & . & . & . & • & 65 & $13 \cdot 0$ \\
\hline \multicolumn{2}{|c|}{ Lumbar spine only . } & . & . & . & • & 1 & $0 \cdot 2$ \\
\hline & Total & . & . & . & • & 500 & 100 \\
\hline \multicolumn{6}{|c|}{ Side involved in cases of lower limb pain } & No. of cases & $\%$ \\
\hline Left side & . & . & . & . & - & 260 & $52 \cdot 0$ \\
\hline Right side & . & . & . & . & . & 195 & 39.0 \\
\hline Bilateral & . & . & . & . & . & 31 & $6 \cdot 2$ \\
\hline \multirow[t]{2}{*}{ Alternating } & . & . & . & . & . & 13 & $2 \cdot 6$ \\
\hline & Total & . & . & . & . & 499 & $99 \cdot 8$ \\
\hline
\end{tabular}

is that back pain from a disc protrusion is seldom so severe, so persistent or so frequent as to require operation. Occasionally, pain affected both lower limbs either simultaneously or in succeeding attacks. In over 90 per cent, however, it was felt in one leg alone, and the left was involved more often than the right in the proportion of $1 \cdot 3: 1$. Others have related this left-sided preponderance to right-handedness. No evidence has been found to support this hypothesis. But the fact that the side of the master hand may not correspond to that of the foot preferred in games, etc., may explain the absence of any such obvious correlation. Certainly it seems that when the lumbar spine is subjected to stress the protective mechanism is less complete on the left than on the right in a significant proportion of individuals. The lower limb pain was posterior (sciatic) in 98 per cent of the patients, and anterior-with or without sciatic pain-in 2 per cent. A careful determination of the peripheral radiation of the pain is important in localising the affected disc: involvement of the heel, sole and outer margin of the foot points to a lumbo-sacral disc lesion; radiation to the dorsum of the foot and hallux suggests protrusion of the disc between the fourth and fifth lumbar vertebrae; and anterior thigh pain radiating across the patella and along the antero-medial surface of the leg points to a lesion at the L.2-3 or L.3-4 interspace.

VOL. 33 B, NO. 1, FEBRUARY 1951 
In Tables III, IV, and V the number of pre-operative attacks of pain, and the total duration of symptoms are recorded. It is noteworthy that one attack of sciatica may persist for as long as five years; that the interval between two severe attacks may be twenty years; and that attacks may recur over a period of twenty-five years. The total duration of symptoms was one year or less in approximately one-third of the patients, and over one year in the remaining two-thirds. Table $\mathrm{V}$ shows the duration of the pre-operative attack of pain. This was one year or less in almost three-quarters of the patients and over one year in the remainder. In Table VI the frequency of symptoms other than pain is noted. Paraesthesiae in the lower limb were very common; their peripheral distribution has the same localising significance as

TABLE III

Number of Pre-operative Attacks of Pain

\begin{tabular}{|c|c|c|c|c|c|}
\hline \multicolumn{4}{|c|}{ Number of attacks } & No. of cases & $\%$ \\
\hline One attack only & . & . & . & 252 & $50 \cdot 4$ \\
\hline Two attacks & . & . & . & 76 & $15 \cdot 2$ \\
\hline Three or more attacks & . & & . & 172 & $34 \cdot 4$ \\
\hline Total & . & • & . & 500 & 100 \\
\hline
\end{tabular}

that of the pain. Twenty-one patients (4.2 per cent) complained of severe weakness in one or both legs; in five of these the picture was one of a severe cauda equina lesion with the characteristic motor, sensory and sphincter disturbances; in the remainder it involved one lower limb only, where dorsiflexion and eversion of the foot and extension of the toes were particularly affected. Severe disturbance of vesical control was limited to the five patients with the cauda equina syndrome. In five others, however, increased frequency or difficulty of micturition developed in association with the sciatic pain.

The investigation of the patient must include a thorough general examination and a digital examination of the pelvis. Clinical signs due to an intervertebral disc protrusion fall into

TABLE IV

TOtal DuRation of Symptoms

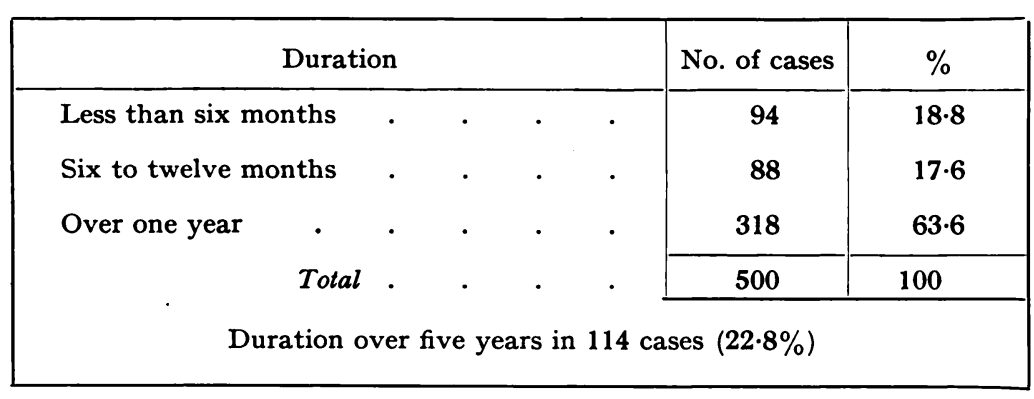

three groups-spinal, tension and neurological signs. The spinal and tension signs supply information concerning the size of the protrusion and its relationship to the extradural nerve and theca. They are especially valuable in assessing the severity of the patient's pain. The neurological signs indicate the severity of the injury to nerve fibres and assist greatly in determining which extradural nerve-and therefore which intervertebral disc-is affected.

The spinal signs are analysed in Table VII. Reduced mobility is probably always present; flexion is often greatly restricted. In only nine cases was spinal movement but slightly impaired, and in two of these the protrusion was in the upper lumbar region. Hyperextension 
TABLE V

Duration of Attack of Pain Immediately Before Operation

\begin{tabular}{|c|c|c|c|c|c|c|}
\hline \multicolumn{5}{|c|}{ Duration } & No. of cases & $\%$ \\
\hline Less than six months & • & . & . & . & 225 & $45 \cdot 0$ \\
\hline Six to twelve months & • & - & - & . & 140 & $28 \cdot 0$ \\
\hline \multirow[t]{2}{*}{ Over one year } & 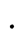 & - & . & • & 135 & $27 \cdot 0$ \\
\hline & $\cdot$ & • & · & $\cdot$ & 500 & 100 \\
\hline
\end{tabular}

TABLE VI

SYMPTOMS OTHER THAN PAIN

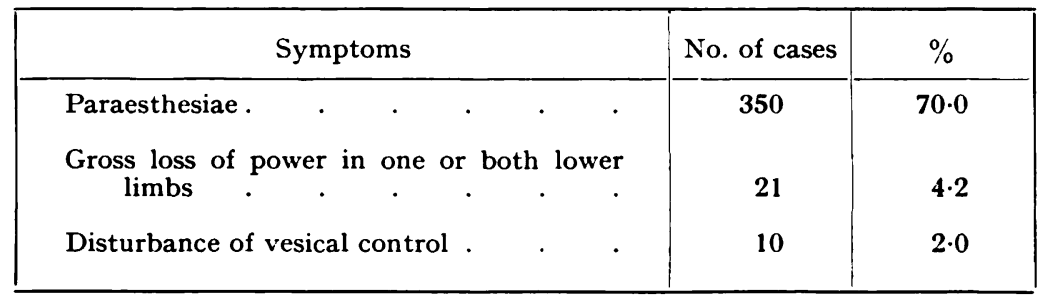

TABLE VII

SPINAL SignS

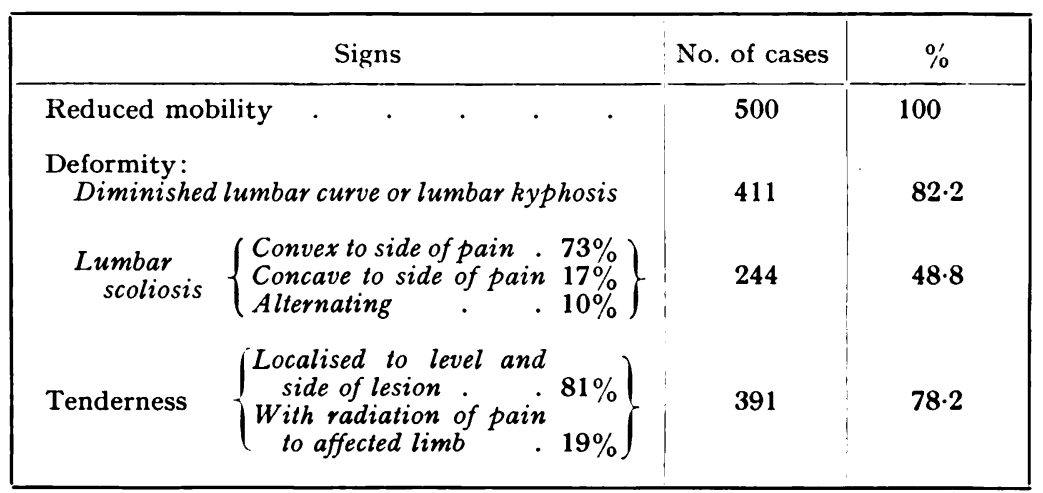

TABLE VIII

TENSION Signs

\begin{tabular}{|c|c|c|c|c|c|c|c|c|c|}
\hline \multicolumn{8}{|c|}{ Signs } & \multirow{2}{*}{$\begin{array}{l}\text { No. of cases } \\
495 \\
\text { (Test negat } \\
\text { patients, all } \\
\text { lumbar disc }\end{array}$} & \multirow{2}{*}{$\begin{array}{c}\% \\
99 \\
\text { tive in five } \\
\text { with upper } \\
\text { protrusion) }\end{array}$} \\
\hline $\begin{array}{l}\text { Positive straight leg raising test } \\
\text { (At angle greater than } 75^{\circ} . \\
\text { (At angle less than } 75^{\circ} .\end{array}$ & $\cdot$ & $\begin{array}{l}.25 \% \\
.75 \%\end{array}$ & & . & - & - & - & & \\
\hline Positive drop test & . & . & . & . & . & . & . & \multicolumn{2}{|c|}{$\begin{array}{l}\text { Most cases in which } \\
\text { straight leg raising } \\
\text { was restricted }\end{array}$} \\
\hline Positive femoral nerve stretch tes & & . & . & . & . & . & . & \multicolumn{2}{|c|}{$\begin{array}{l}\text { All cases of protrusion } \\
\text { of } L .2-3 \text { and } L .3-4 \text { discs }\end{array}$} \\
\hline Positive neck flexion test or $\mathrm{Naff} z$ & gger & test & . & . & . & . & . & \multicolumn{2}{|c|}{ Many cases } \\
\hline
\end{tabular}

VOL. 33 B, NO. 1, FEBRUARY 1951 
is frequently painful, particularly when the protrusion affects one of the upper lumbar discs. Attempts to correct a lateral tilt often produce pain in the affected lower limb. Lumbar tenderness at the level of the protrusion was seen in almost 80 per cent of the patients. In a quarter of these pressure at the most tender point caused pain to radiate into the lower limb. Deformity was present in over 80 per cent of cases; reduction of the normal lumbar lordosis was most frequent, sometimes amounting to a lumbar kyphosis. Lumbar scoliosis was seen in almost 50 per cent of cases; the convexity was usually towards the painful limb, but sometimes away from it. Occasionally it could be made to alternate. A particular posture or deformity is probably adopted to lessen the painful stretching and compression of the extradural nerve. In certain postures the pressure exerted by body weight on the affected intervertebral disc will be reduced, with consequent diminution in the size of its protruded part. It is probable also that the relationship of the extradural nerve to the protrusion is varied by alterations in spinal posture; possibly displacement of both protrusion and extradural nerve may give rise to such variation in relationship. In the common type of

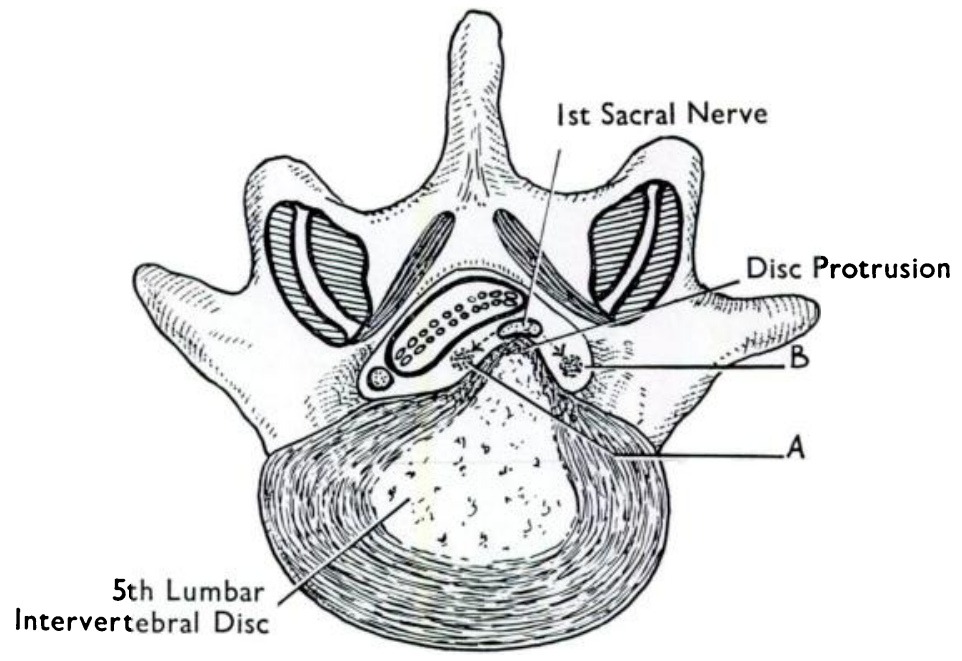

FIG. 3

Diagram of a section through the lumbo-sacral intervertebral disc. It is believed that when the extradural nerve lies on the summit of the protrusion pain is greatest and that when it is displaced to the medial or lateral side of this summit pain is reduced. Thus may be explained the occurrence of an alternating scoliosis.

protrusion, with its summit lateral to the nerve, the lower lumbar scoliosis is convex to the painful side. Such a posture may serve to separate the nerve from the summit of the protrusion and thus diminish lower limb pain. With the less common type of protrusion, lying medial to the extradural nerve, the scoliosis is frequently concave to the painful side, and perhaps here the deformity again serves to reduce pain by separating the nerve from the summit of the protrusion. The relationship of the protrusion to the extradural nerve can often though not always be predicted before operation on the basis of this hypothesis. Further, in patients with an alternating scoliosis it has been repeatedly observed that pain is greatest when the scoliosis is corrected and is relieved with a tilt to either side. Operation in these cases has almost always revealed a freely mobile nerve and a protrusion with a trough on each side of its summit (Fig. 3). When pain is greatest and the spine straight, the extradural nerve lies on this summit; when there is a lateral tilt in one direction or the other it lies in either the medial or the lateral trough. 
The tension signs are indicated in Table VIII. The normal state of tension in the lumbar extradural nerve has already been emphasized as an important cause of symptoms. The relevant signs depend upon increase in this tension by a lumbar disc protrusion: certain positions of the head, trunk and limbs, and alterations in cerebro-spinal fluid pressure, which

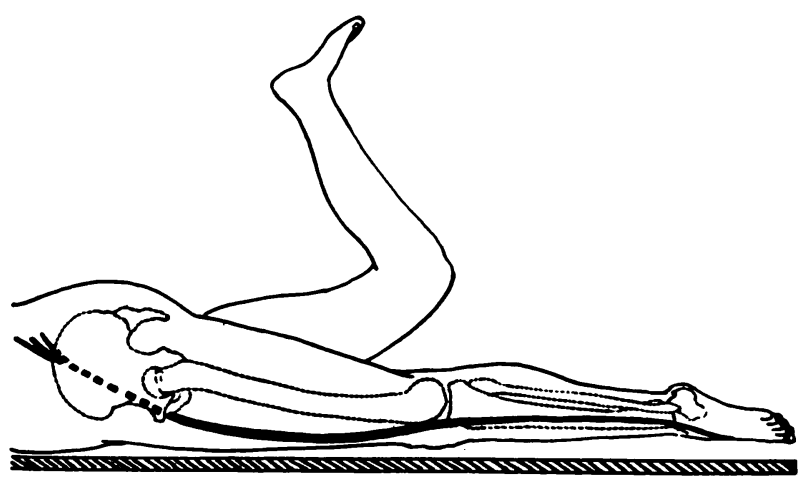

Fig. 4

Representation of the femoral nerve stretch test, which is of value in the diagnosis of upper lumbar disc protrusions. further increase this tension, so aggravate the pain. These signs are of value not only in determining the presence and relationships of a lumbar disc protrusion but also in assessing the severity of the pain (O'Connell 1943, 1946). From dissection in the cadaver it has been found that flexion of the head and neck produces a cephalad movement of the dural theca and the consequent increase in the tension in the extradural nerves within the spinal canal, particularly the longitudinally disposed lumbar and sacral nerves. In the same way

it has been observed that when the hip is fully flexed, with the knee extended and the ankle dorsiflexed, a caudal movement of the theca occurs and tension in the extradural nerves entering the sacral plexus is at its greatest. The extradural nerves entering the femoral nerve (second, third and fourth lumbar nerves) are made tense not by this manoeuvre but by extension of the hip and flexion of the knee. Thus is explained the basis of the straight leg raising and femoral nerve stretch tests (Fig. 4). During operations upon the lumbar spine in the lateral position these findings have been confirmed. Further, it has been noted that with jugular compression the theca swells and the upper attachment of the extradural nerve is carried laterally - its lower extremity remaining fixed in the intervertebral foramen. In the common relationship in which the protrusion is lateral to the extradural nerve, this movement will frequently increase the pain. Occasionally jugular compression relieves the pain and in such cases the extradural nerve is usually found to be lateral to the summit of the protrusion. Similarly neck flexion often aggravates the pain of a lateral protrusion because it draws the nerve towards the highest
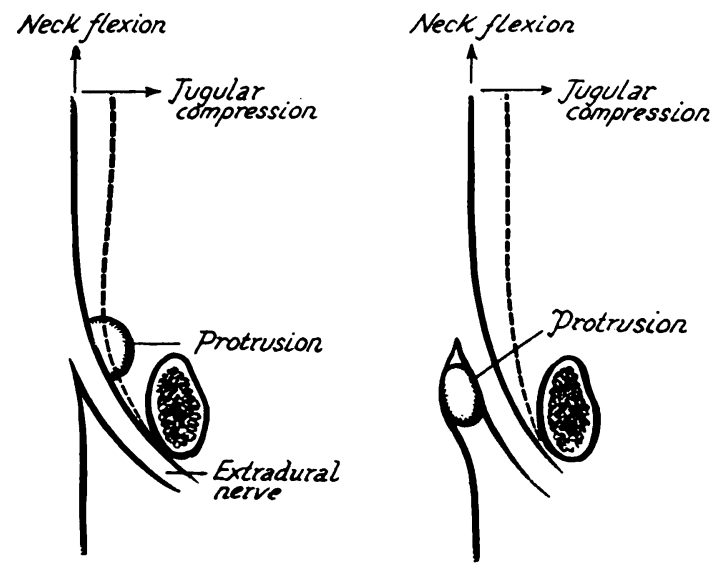

FIG. 5

Diagram to indicate the value of neck flexion and jugular compression in the clinical determination of the relationship of protrusion to extradural nerve. On the left is shown a lateral protrusion, and since either neck flexion or jugular compression displaces the nerve towards its summit each increases the pain. On the right is a medially placed protrusion; either procedure will displace the nerve from the protrusion and thus diminish pain. part of the mass. With a medially placed protrusion neck flexion has the effect of displacing the nerve to a lower part of the mass and may relieve the pain (Fig. 5). Neck flexion and jugular compression therefore assist, as does the nature of a scoliosis, in determining the relationship of nerve to protrusion. When these manoeuvres alone do not influence the pain it will frequently be found that they do so if 
TABLE IX

Neurological Signs

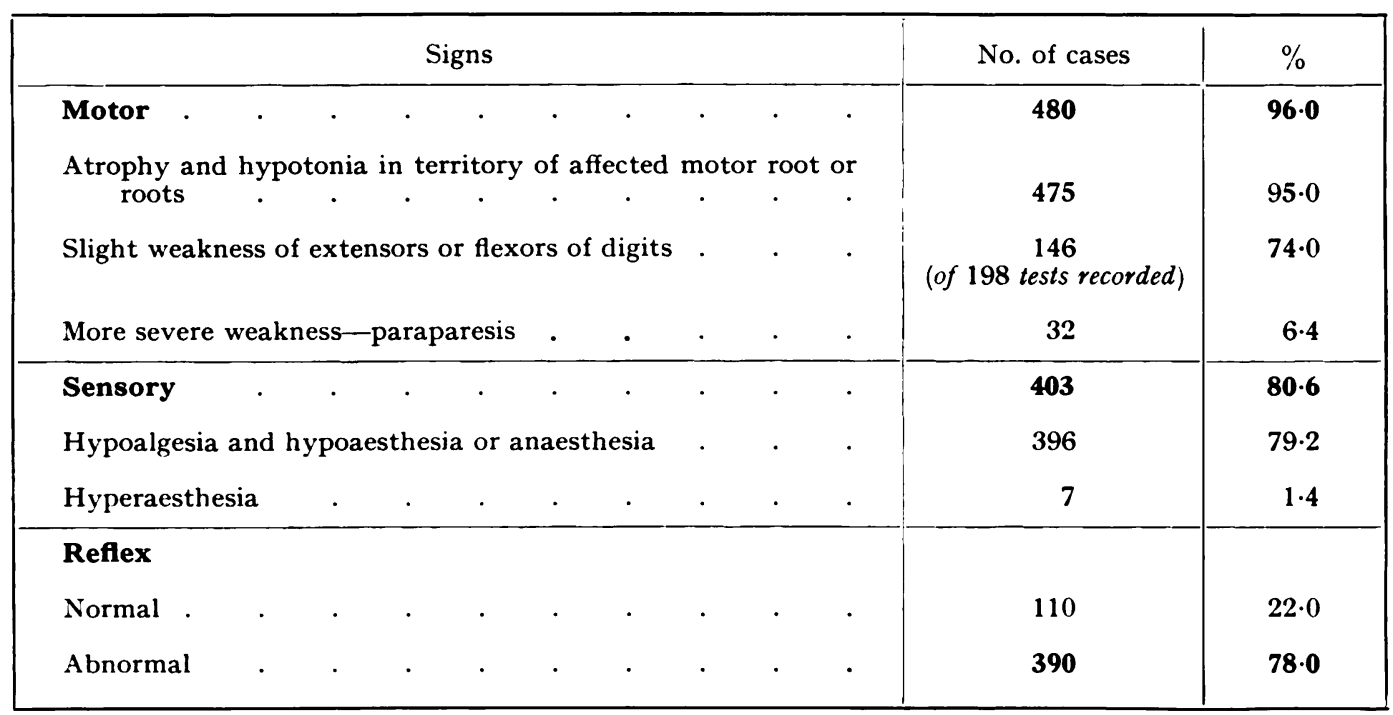

combined with straight leg raising. When it has been found difficult to assess the severity of pain, and when there has been doubt at what angle straight leg raising aggravates it, the drop test has been found of value. In cases of lower lumbar disc protrusion both straight legs can frequently be raised together to a higher angle, without causing pain, than can the limb on the painful side alone. If this is done and the sound limb is allowed to drop on to the bed, a well-marked increase in pain will often testify to increased tension in one of the extradural nerves entering the sacral plexus. It has been suggested in the literature that straight leg raising increases crural pain by movement of the lumbar vertebrae. That this is relatively unimportant may be demonstrated by obliterating the lumbar curve by fully flexing the hip and knee on the sound side; the angle at which the straight leg raising test then aggravates the pain is little changed.

The neurological signs are indicated in Table IX. Motor disturbance was seen in 96 per cent,

TABLE X

ANalysis of Reflex Disturbance

\begin{tabular}{|c|c|c|c|}
\hline & & No. of cases & $\%$ \\
\hline $\begin{array}{l}\text { L.5-S.1 protrusions (248 cases): } \\
\text { reflexes normal } \\
\text { ankle jerk reduced or absent } \\
\text { knee jerk reduced or absent }\end{array}$ & & $\begin{array}{r}36 \\
211 \\
7\end{array}$ & $\begin{array}{r}14.5 \\
85.0 \\
2 \cdot 8\end{array}$ \\
\hline $\begin{array}{l}\text { L.4-5 protrusions (198 cases): } \\
\text { reflexes normal } \\
\text { ankle jerk reduced or absent } \\
\text { knee jerk reduced or absent }\end{array}$ & . & $\begin{array}{r}68 \\
129 \\
10\end{array}$ & $\begin{array}{r}34 \cdot 0 \\
65 \cdot 1 \\
5 \cdot 0\end{array}$ \\
\hline $\begin{array}{l}\text { Double protrusions (46 cases): } \\
\text { reflexes normal } \\
\text { ankle jerk reduced or absent } \\
\text { knee jerk reduced or absent }\end{array}$ & . & $\begin{array}{r}6 \\
38 \\
3\end{array}$ & $\begin{array}{r}13 \cdot 0 \\
82 \cdot 6 \\
6.5\end{array}$ \\
\hline $\begin{aligned} \text { L, } 2-3 \text { and L. } & \text { - }-4 \text { protrusions ( } 8 \text { cases): } \\
& \text { reflexes normal } \\
& \text { ankle jerk reduced or absent } \\
& \text { knee jerk reduced or absent }\end{aligned}$ & . & $\begin{array}{r}\text { nil } \\
6 \\
4\end{array}$ & $\begin{array}{l}\overline{75 \cdot 0} \\
50 \cdot 0\end{array}$ \\
\hline
\end{tabular}


sensory disturbance in $\mathbf{8 0 . 6}$ per cent, and reflex disturbance in $\mathbf{7 8}$ per cent. Taken in conjunction with the radiographic findings these signs are of first importance in determining the particular disc affected. Motor disturbance contributed least information but sensory and reflex changes were of great value. Thus sensory impairment on the sole and outer margin of the foot (first sacral dermatome) with absence of the ankle jerk pointed to a lumbosacral disc protrusion; sensory impairment on the dorsum of the foot (fifth lumbar dermatome) without alteration of the ankle jerk suggested a protrusion of the L.4-5 disc; and impairment of sensibility extending from the patella along the antero-medial surface of the lower leg, with reduction of the knee jerk, pointed to a protrusion of one of the upper lumbar discs (L.2-3 or L.3-4).

The state of the tendon reflexes in the lower limbs is shown in Table X. Normal tendon reflexes were never seen in the presence of an upper lumbar disc protrusion. They were normal more often when the protrusion affected the L.4-5 disc than when the lumbo-sacral or both the lower lumbar discs were involved. Reduction or absence of the ankle jerk was usually associated with a lumbo-sacral protrusion but was common with protrusions at all

TABLE XI

Accessory Methods of Diagnosis

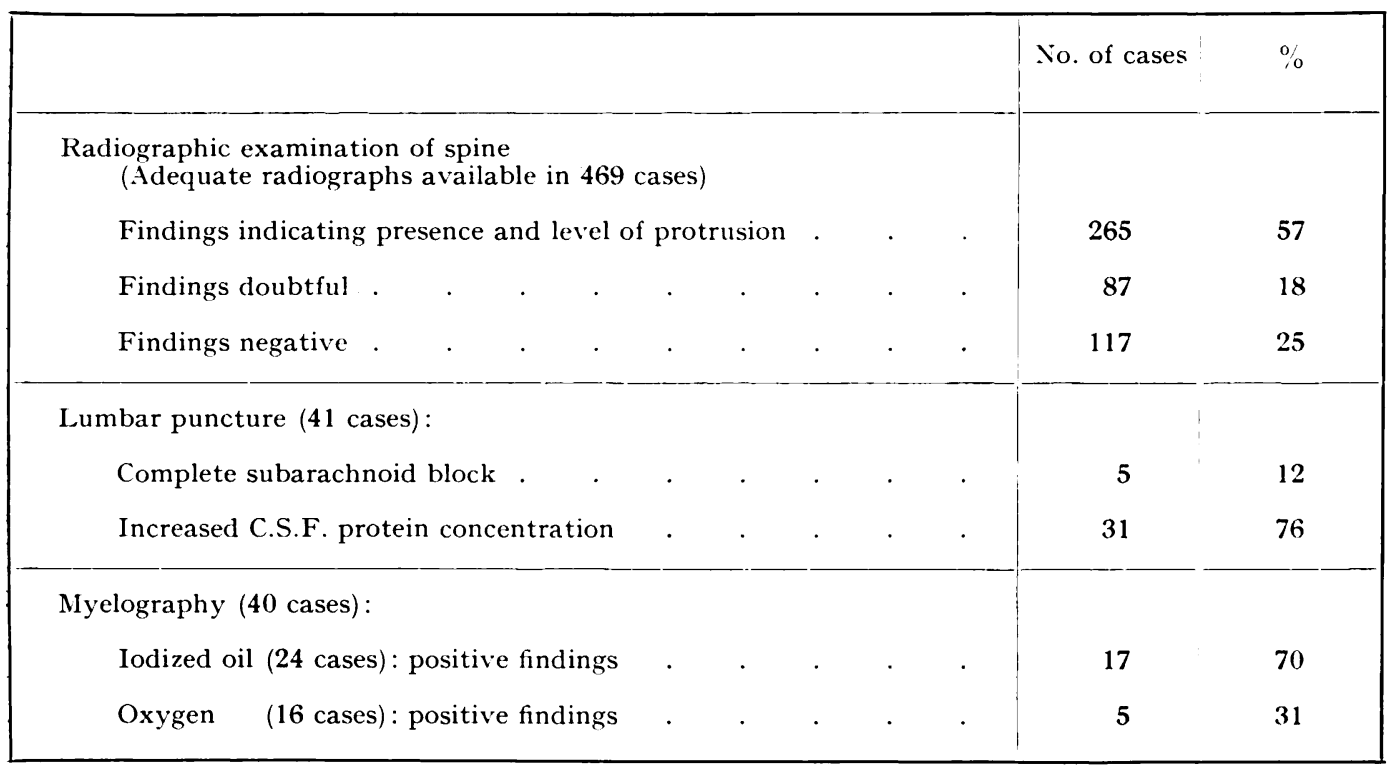

levels. Absence or reduction of the knee jerk was most common with protrusion of one of the upper lumbar discs but also occurred, in diminishing frequency, with double protrusions, with protrusions of the L.4-5 disc, and with lumbo-sacral protrusions. Although pain is caused by stretching or compression of one intraspinal extradural nerve, impairment of the ankle jerk in cases of high lumbar protrusion and of the knee jerk in cases of low lumbar protrusion nevertheless suggests that injury to intrathecal nerve roots plays a part in the development of the neurological picture.

\section{RADIOGRAPHIC EXAMINATION}

Table XI indicates the results of radiographic examination in 469 cases of the series in which adequate information concerning these results was available at the times of the follow-up investigations. Good lumbar and sacral radiographs must be made in every case. They may at once reveal some other responsible lesion such as an intraspinal neoplasm, a primary or

vol. 33 B, No. 1, FEBRUARY 1951 
secondary vertebral growth or tuberculous spondylitis. Secondly, the spinal films may indicate the presence and level of the protrusion by showing narrowing of an intervertebral space with sclerosis of the adjacent vertebral surfaces and perhaps lipping of their margins (Fig. 6). Thirdly the films may show congenital variations in the lumbo-sacral region which are important in the localisation of the affected disc on the basis of neurological signs. It is believed that sacralisation of the fifth lumbar vertebra is more common than is usually stated. When there are only four lumbar vertebrae or when massive fifth lumbar transverse processes are

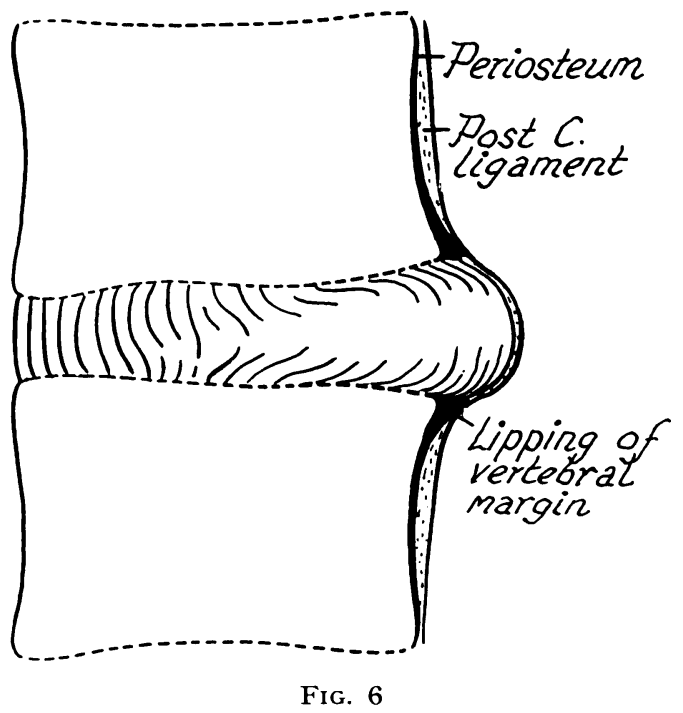

Possible explanation of marginal lipping adjacent to a disc protrusion. The posterior longitudinal ligament, displaced and tautened by the bulging disc, pulls upon the attachment of the periosteum to the posterior vertebral margins; new bone forms beneath the periosteum at the points of tension. partly fused with the sacrum the abnormality is obvious. Far more common is a conditionwhich may be called "occult sacralisation"in which there are five lumbar vertebrae but the last is placed high so that its spine is at or just below the level of the iliac crests, the sacrum is long with perhaps five instead of four foramina, and the last rib is much longer than the true twelfth rib. Here it may well be that the apparent first lumbar vertebra is in reality the last dorsal, and the true fifth lumbar vertebra is fused with the sacrum. Recognition of this abnormality has frequently explained why a protrusion of the last intervertebral disc may give rise to the clinical picture of a protrusion of the disc between the fourth and fifth lumbar vertebrae. There were fifty cases of sacralisation of the fifth lumbar vertebra (10 per cent) and it is noteworthy that its recorded incidence is higher among the later cases in the series.

\section{ACCESSORY METHODS OF DIAGNOSIS}

Lumbar puncture (41 cases), and myelography with lipiodal or oxygen (40 cases), which were performed as a routine in the early cases are now used only in atypical ones and, in particular, when a neoplasm is suspected (Table XI). A clinical diagnosis of a lumbar intervertebral disc protrusion is considered more accurate than a myelographic one. The diagnosis is readily made in most patients by a careful clinical and radiographic examination.

\section{SELECTION OF GASES FOR OPERATION}

The greatest problem is not diagnosis but deciding upon the correct treatment in each case. The natural history of lumbago and sciatica has not been altered by the discovery of their common cause, and the tendency to spontaneous recovery remains as strong as it has been down the centuries. Rest during the stage of acute symptoms, with later exercises for the lumbar muscles and joints, forms the correct treatment in most patients. Only when an adequate trial of such measures fails to bring relief should surgery be considered. It is therefore clear that any discussion of the relative merits of conservative and surgical treatment is profitless, because surgery should be reserved for cases in which other measures fail. This series of 500 patients treated surgically represents but a small proportion of the patients seen in the out-patient department in whom a clinical diagnosis of protruded lumbar intervertebral 
disc has been made. It is difficult to determine what proportion of patients with disc protrusions require operation. Before a patient attends a neurosurgical clinic he will have been seen by a general practitioner and often also by a general physician, a neurologist or an orthopaedic surgeon: many of the milder cases are so filtered off and never reach the neurosurgeon. Of the patients referred to the neurosurgical out-patient clinic at St Bartholomew's Hospital, less than 20 per cent are submitted to operation. The only absolute indication for operation is the sudden development of severe neurological disturbance from involvement of the cauda equina by a large protrusion. This clear indication for surgery was present in $\mathbf{2}$ per cent of our cases; in the remainder the operative indications were relative. Important factors are the severity and duration of pain and the frequency of recurring attacks. The severity of the pain is assessed from the history, from the tension signs and from the degree of disability. When these suggest that the emotional accompaniment of pain is excessive and that the symptom is one of discomfort or aching rather than pain, operation is avoided. Operation is seldom undertaken unless the duration of symptoms exceeds three months. But if pain is intense or if short sharp attacks recur at brief intervals this arbitrary minimum period of conservative treatment may be shortened.

\section{AIMS AND TEGHNIQUE OF OPERATION}

In operating there are three objects. The first is to remove the protruded fragments of disc. If there are well-marked projections of the vertebral margins above and below the protrusion these are removed at the same time. (In Figure 6 a possible explanation of the

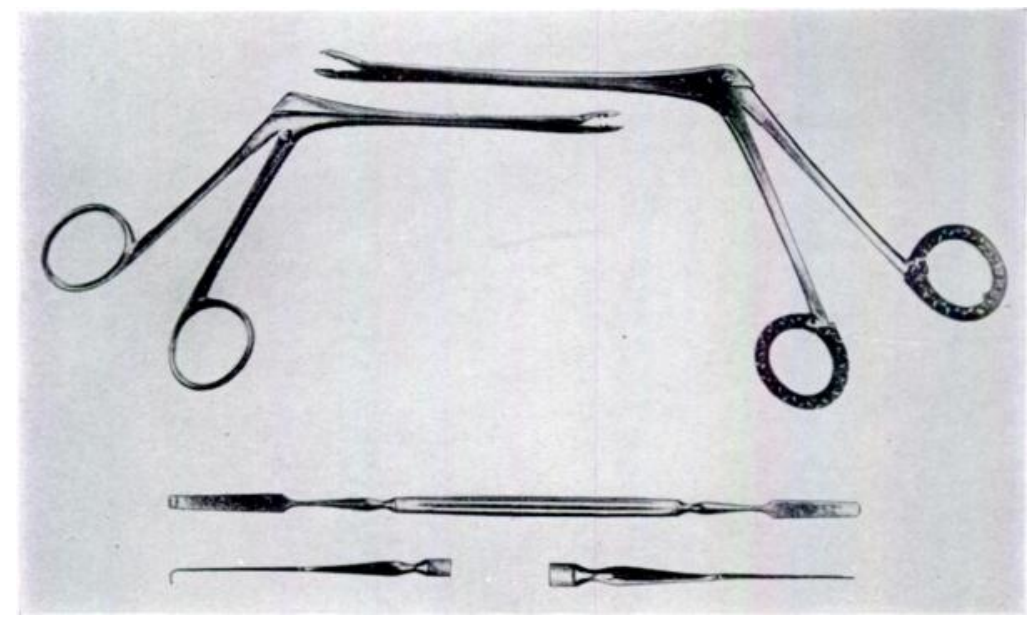

FIG. 7

Nerve retractor and (above) pituitary rongeurs used in the removal of intervertebral disc protrusions.

development of this lipping is illustrated.) Secondly, adhesions between the nerve and the posterior longitudinal [common] ligament or the annulus fibrosus are divided to reduce the tension within the nerve as much as possible. Thirdly, an effort is made to clear the intervertebral interval of as much disc tissue as possible to lessen the risk of recurrence.

The development of the operation, in our hands, is indicated in Figures 8 to 11. In the first four cases the protrusion was removed by the transdural route after wide laminectomy (Fig. 8). Subsequently the exposure was extradural in all cases and the amount of bone removed was gradually reduced until, after seventy-five operations, a single spinous process and the related lamina on the side of the lesion were alone removed (Fig. 9). Our present technique was developed after $\mathbf{1 3 0}$ cases had been dealt with. The exposure is limited to stripping the

vol. 33 B, No. 1, FEBRUARY 1951 
J. E. A. o'CONNELL

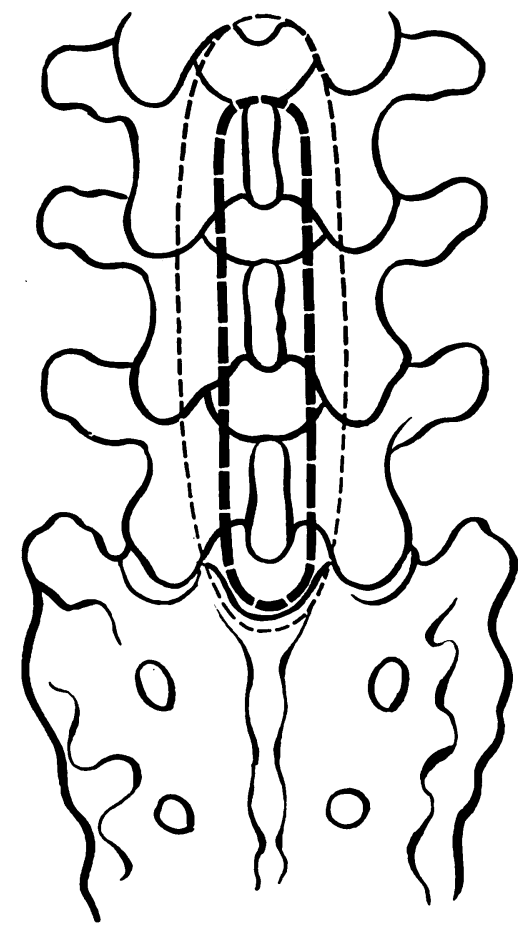

FIG. 8

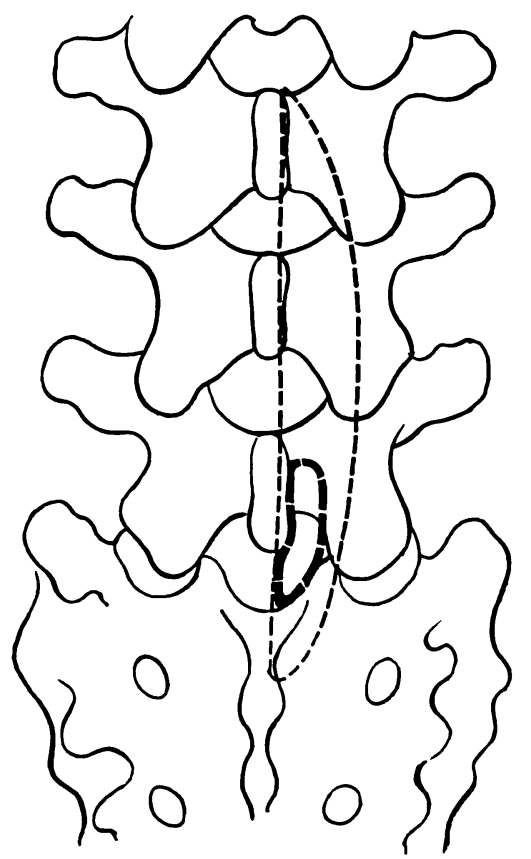

FIG. 10

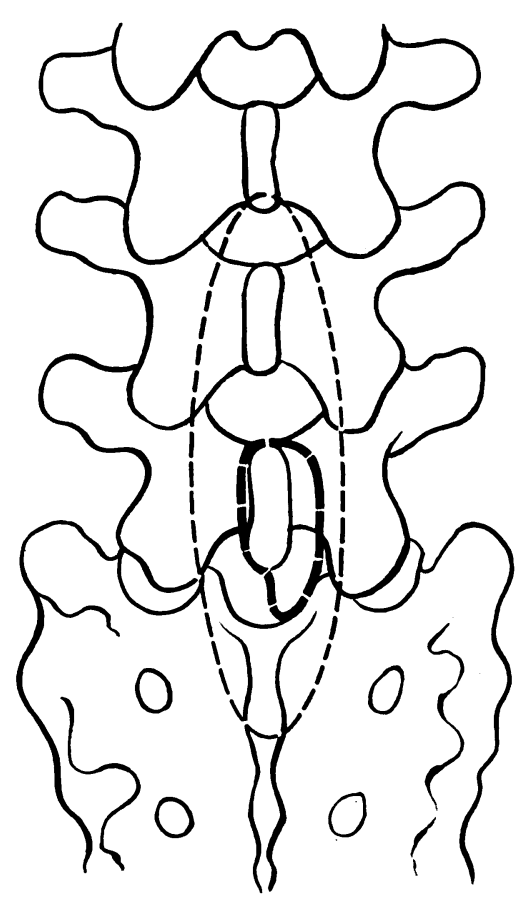

FIG. 9

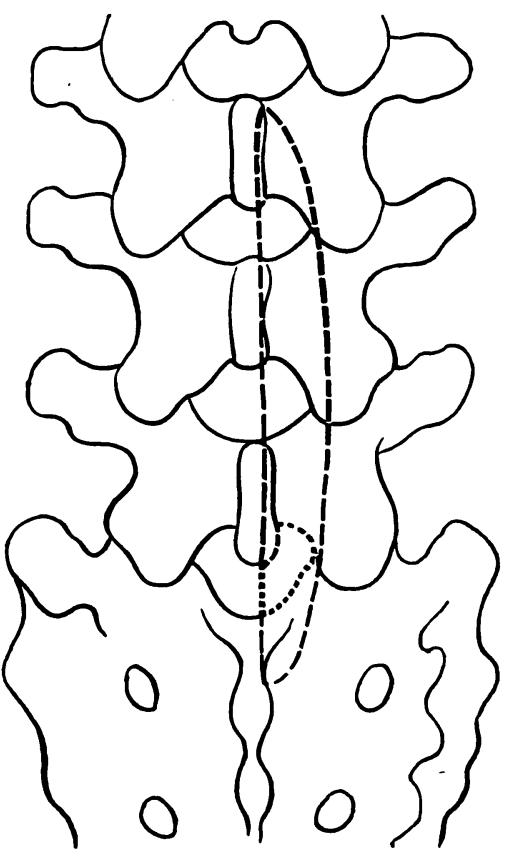

FIG. 11

Evolution of the exposure used in excision of intervertebral disc protrusions. Figure 8, wide laminectomy; transdural approach. Figure 9, removal of one spinous process and one lamina after bilateral stripping of spinal muscles. Figure 10, unilateral stripping of muscles and incomplete removal of one lamina with the ligamentum flavum caudal to it. Figure 11, interlaminar approach without removal of bone. 
muscles from the vertebral spinous processes and laminae on the side of the lesion and excising part of the lower margin of the lamina of the vertebra above the interval to be explored (Fig. 10). If the interval between the laminae is wide it may be unnecessary to remove any bone (Fig. 11). The stages of the operation are shown in Figures 12 to 19, and some of the instruments in Figure 7. When there is any doubt as to the adequacy of the operative findings at a particular level the adjacent disc is explored in the same way. Exposure of two or more levels was undertaken in 21.8 per cent of cases. If the patient has had well-marked bilateral pain of some duration the affected disc is exposed by an approach similar to that described above but on both sides: although most of the disc contents can usually be removed through a unilateral exposure, adhesions on the opposite side would be left undivided and might lead to persistent symptoms on that side. Posterior rhizotomy was performed in only two patients,

TABLE XII

Findings at Operation

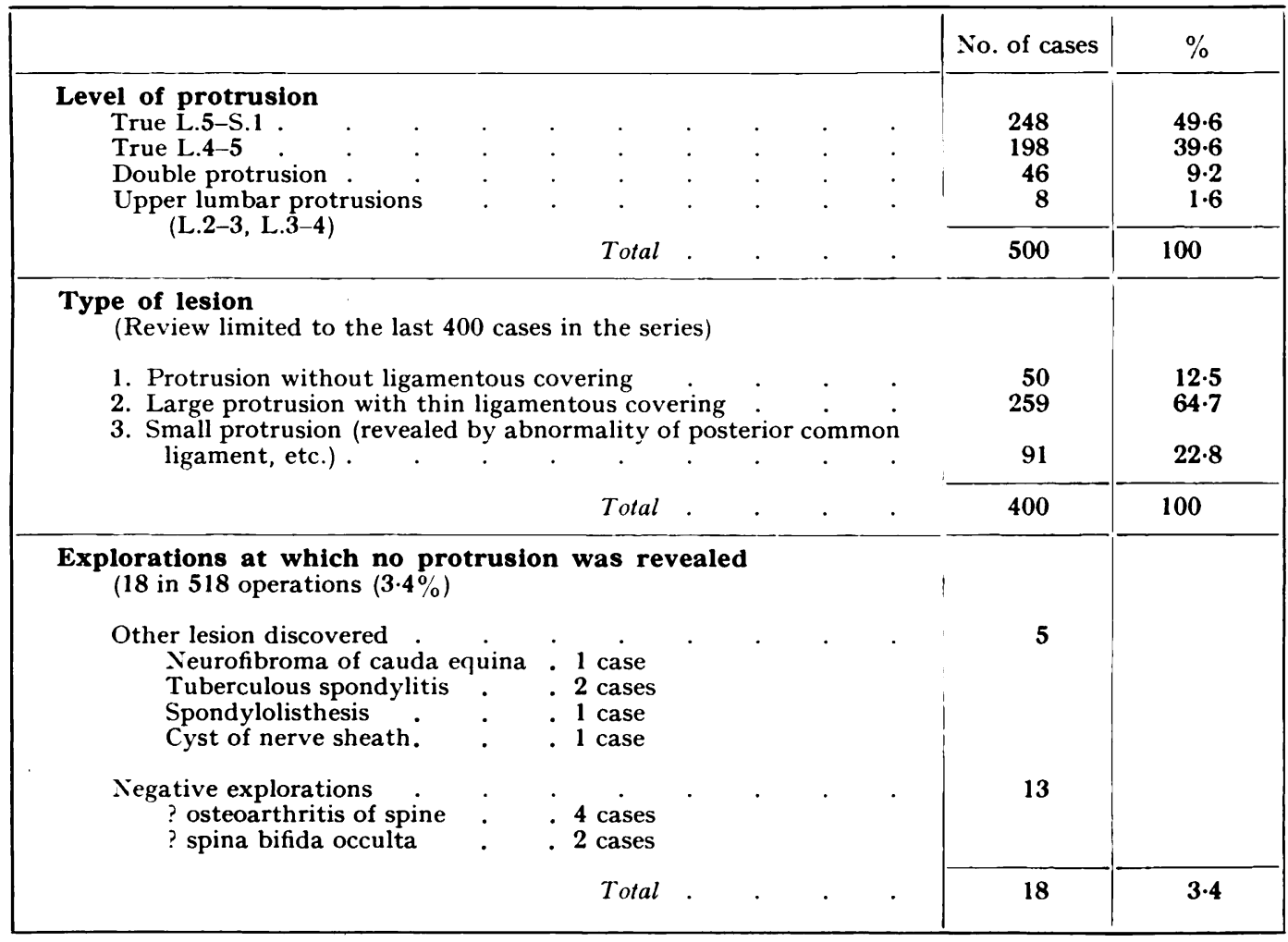

both of whom had recurrent protrusions. In no case was a spinal fusion done: we have, however, a small group of patients not included in the present series in whom a combined exploration and fusion was undertaken with an orthopaedic colleague. These patients complained of backache only and it was considered clinically that they were unlikely to benefit from intervertebral disc surgery-an impression which was confirmed by the operative findings in each instance.

Post-operative treatment-After operation the patient is encouraged to move freely in bed, and he usually gets up on the eighth post-operative day. Spinal exercises are begun on the tenth day and most patients are discharged, able to touch their toes, three weeks after operation. All are instructed to continue regular spinal exercises-a routine that we consider most important.

vol. 33 B, No. 1 , FEBRUARY 1951 


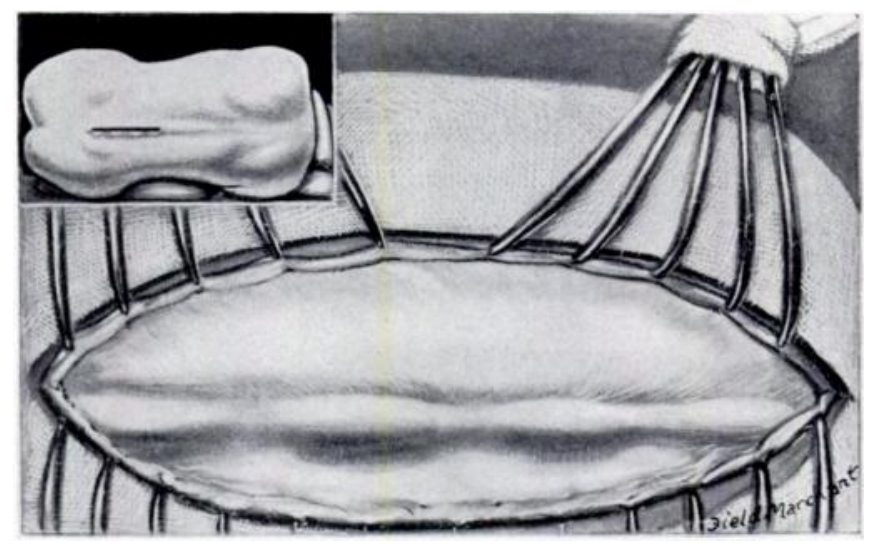

FIG. 12

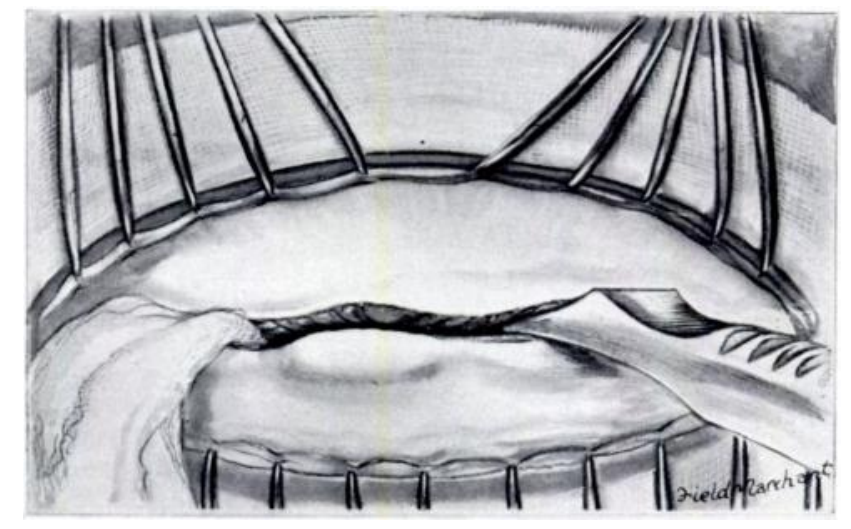

FIG. 13

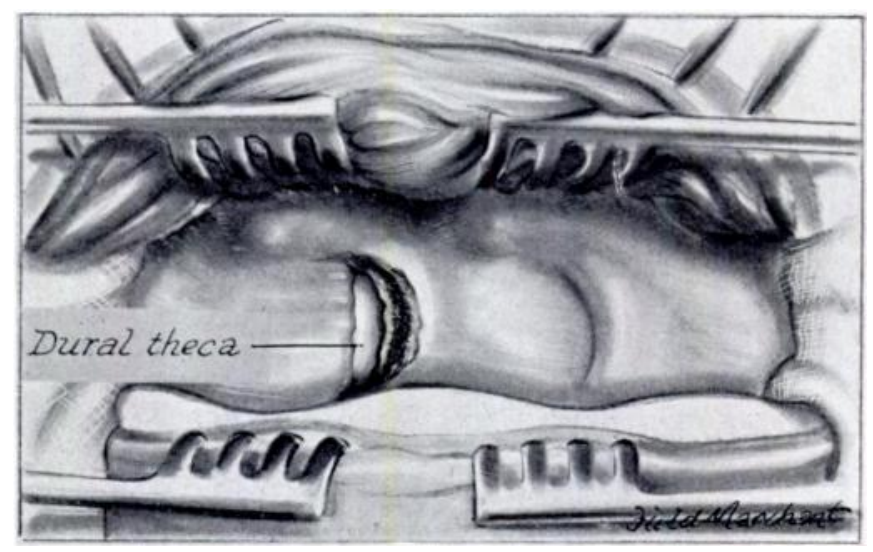

FIG. 14

Technique of operation for excision of lumbo-sacral disc protrusion. Figure 12, the incision; inset shows position of patient. Figure 13, the sacrospinalis (erector spinae) mass is separated subperiosteally from the upper sacral and lower lumbar spines and laminae on the side of the lesion. Figure 14, the lower part of the fifth lumbar lamina is excised on the side of the lesion. Note the deep self-retaining retractors. 


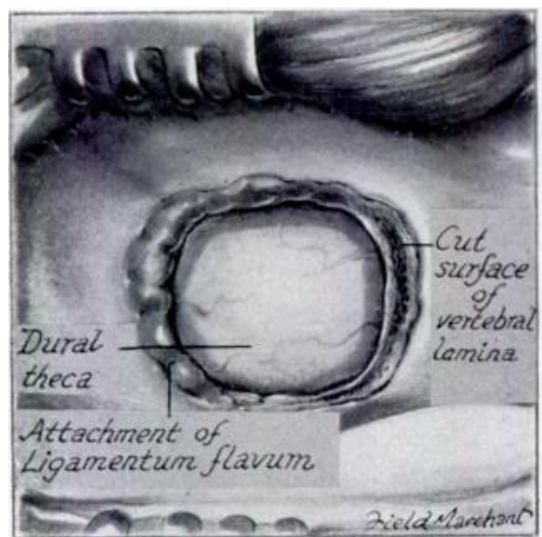

FIG. 15

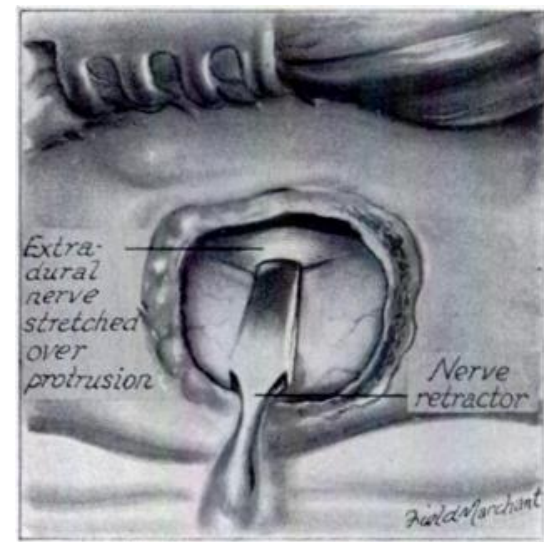

FIG. 16

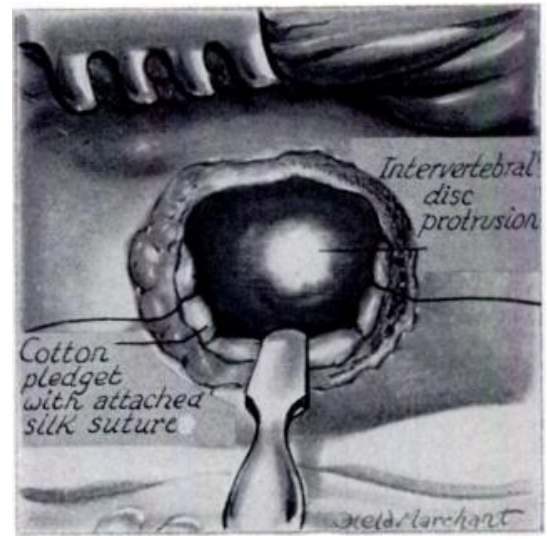

FIG. 17

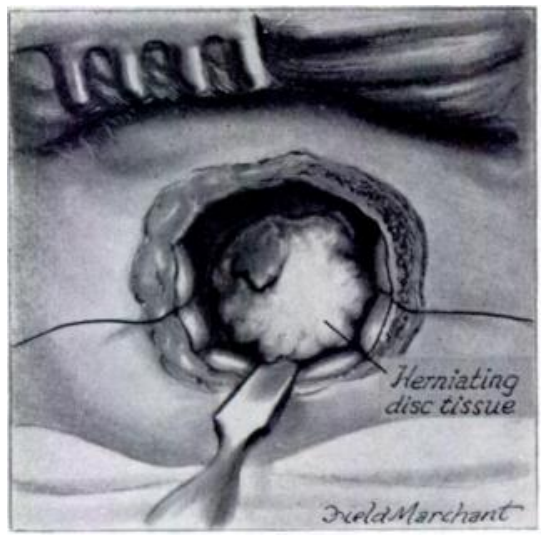

FIG. 18

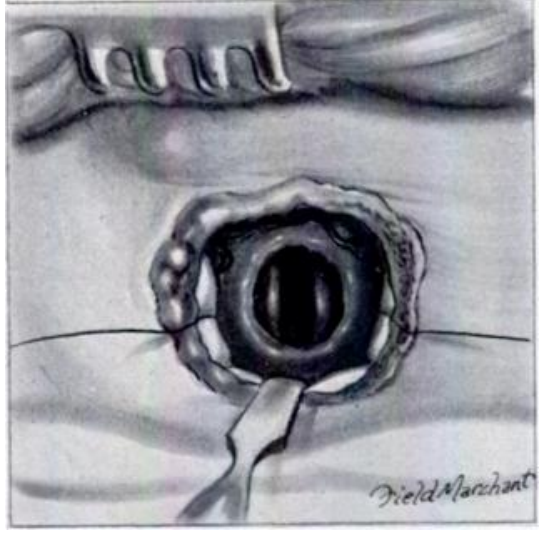

FIG. 19

Figure 15, the ligamentum flavum is resected and the dural theca exposed. Figure 16, the extradural nerve crossing the protrusion is displayed. Figure 17, retraction of the extradural nerve and theca reveals dome of protrusion covered by posterior longitudinal ligament. Figure 18, the ligament is incised and disc tissue escapes under pressure. Figure 19, the protrusion has been excised and the intervertebral interval has been cleared of disc tissue as completely as possible. 


\section{FINDINGS AT OPERATION}

The operative findings are shown in Table XII. The lesion was usually found at either the fourth or the fifth lumbar disc-lumbo-sacral disc protrusions being the more common. It is noteworthy that in the ten-year period during which the 500 operations for lumbar intervertebral disc protrusions were performed, seven cervical and three thoracic [dorsal] disc protrusions were excised. The relatively great size of the lumbar intervertebral discs and their position in a mobile region of the spine, which is subjected to greater stresses in weight-bearing and on movement than any other, together no doubt explain the greater frequency with which the lumbar disc protrusions demand operation.

While it is agreed in the literature that the last two lumbar discs are those usually involved, in some series the lumbo-sacral disc has been the one most frequently affected and in others the disc between the last two lumbar vertebrae. In the present series it was found that the last lumbar disc was the site of the protrusion in 60 per cent and the disc above this in 30 per cent. However, this statement does not indicate accurately the true level of the
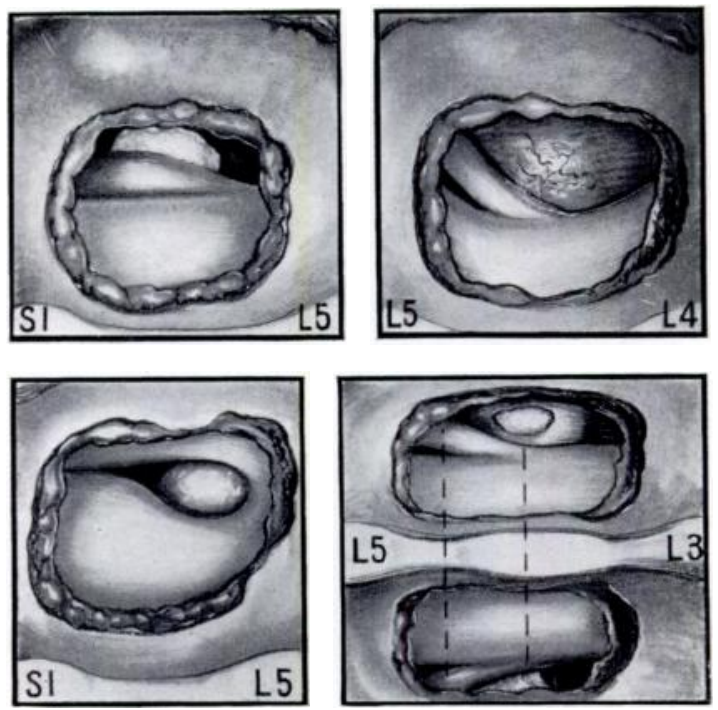

FIG. 20

Types of lesion encountered. Above, left-a protrusion which has penetrated the posterior longitudinal ligament. Above, right-a small protrusion revealed by vascularisation and loss of lustre of the posterior longitudinal ligament, and by adhesions between it and the extradural nerve. Below, left-a medial protrusion presenting in the axilla of the extradural nerve. Below, rightbilateral exposure in a case of persistent bilateral sciatic pain. On the left side a protrusion has penetrated the posterior longitudinal ligament. On the right side there are adhesions between the nerve and the ligament.

protrusion. It has been mentioned previously that sacralisation of the fifth lumbar vertebra, especially of a hidden type, occurs with some frequency. It was considered that in fifty cases of protrusion of the last intervertebral disc this disc was not anatomically the lumbo-sacral disc but that between the fourth and fifth lumbar vertebrae. Allowing for this correction the incidence of protrusion of the disc between the fifth lumbar and first sacral vertebrae falls to 50 per cent and that of the disc between the fourth and fifth lumbar vertebrae rises to $\mathbf{4 0}$ per cent.

In Table XII the type of lesion found is classified in terms which facilitate its recognition and description (see also Fig. 20). The large protrusions with or without a ligamentous 
covering should be recognised easily, though care is necessary not to overlook those placed medially beneath the theca. A thorough exploration in a bloodless field is required to reveal the small protrusions. Here there may be little or no intraspinal projection of disc tissue to be seen at operation, but the extradural nerve may be adherent to the posterior longitudinal ligament: this structure has lost its usual lustre or may be roughened by adhesions, and groups

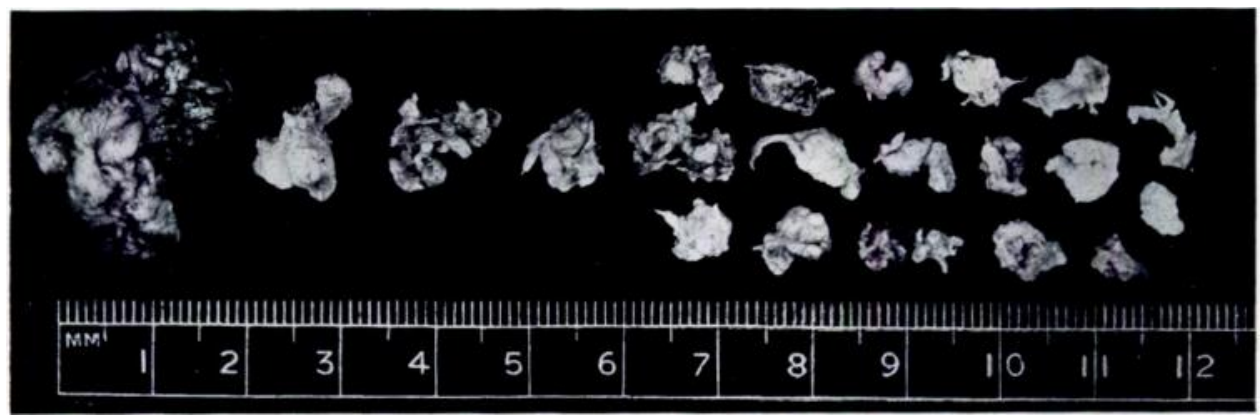

FIG. 21

Typical specimen of intervertebral disc material removed at operation. Weight 2.9 grammes.

of small new blood vessels may be present in it. Sometimes a soft spot in the underlying annulus fibrosus may be palpated. These findings probably indicate a healed or healing stage of a severe injury to the posterior longitudinal ligament and annulus, and tension-producing adhesions between nerve and ligament are frequently the only obvious cause of the symptoms. Excellent results may follow the treatment of this lesion, which has been called the "concealed disc." The term is an unfortunate one: it is surely better to indicate how a particular type of protrusion may be recognised than to suggest to the surgeon that it may be hidden from him-a suggestion that may lead to an unwarranted attack on faultless intervertebral discs. Weight of disc tissue removed - It has been found valuable to record routinely the weight of the disc tissue removed. At post-operative follow-up examinations the figure tells something of what was accomplished at operation. It is important to weigh the specimen without immersion, which even for a short period considerably increases the weight. Thus the average weight of the seventy-six specimens of disc tissue before immersion in fixative was $\mathbf{1 . 9 5}$ grammes; after fixation in formol-saline for twenty-four hours the average weight was $3 \cdot 14$ grammes - an increase of 60 per cent. The specimens of ligamentum flavum removed at these operations were weighed as controls, and it was found that the average weight before immersion was 0.57 grammes and that after fixation 0.63 grammes-an increase of 11 per cent. These observations suggest that after its escape from within the annulus fibrosus the turgid nucleus pulposus loses fluid into the extradural space-a loss which may be important in diminishing the size of the protrusion. In a series of 350 specimens the weight before immersion was less than 1 gramme in 14 per cent; $1-2$ grammes in 32 per cent; $2-3$ grammes in 31 per cent; $3-5$ grammes in 21 per cent; and over 5 grammes in only 2 per cent. The average weight of a series of lumbar intervertebral discs excised completely at autopsy was $\mathbf{2 4 \cdot 6}$ grammes. Thus only exceptionally does the specimen removed at operation represent more than 20 per cent by weight of the average normal intervertebral disc, although in the present series an effort was always made to remove not only the protrusion but as much as possible of the undisplaced disc tissue (Fig. 21). The average total weight of a series of lower cervical discs removed at autopsy was just under 1 gramme-only 4 per cent of the weight of a lumbar disc. This may explain why root symptoms from a cervical disc protrusion seldom persist, whereas with the larger lumbar discs persistence of such symptoms is relatively common. 
During the period of this investigation, when 500 disc protrusions were removed, eighteen explorations (3.4 per cent) were undertaken without finding a disc protrusion. These cases are analysed in Table XII. In five patients another cause for the symptoms was discovered. The remaining thirteen operations $(2.5$ per cent) are classified as negative explorations, but spina bifida occulta was present in three and osteoarthritis of the spine in four, and these conditions may have had a bearing on the symptoms. Thus only in six cases was no adequate lesion revealed. It is noteworthy that seven of the thirteen negative explorations occurred in the first twenty-six patients treated surgically.

\section{MORTALITY}

There were two post-operative deaths in the series-a mortality rate of 0.4 per cent. The first was in a man of fifty-six years with pulmonary and urogenital tuberculosis. He developed a urinary and pulmonary infection and a late wound infection, and died nineteen days after operation. The second death was in a man of thirty years who developed abdominal pain and rigidity six days after operation. The abdomen was explored but no cause for the symptoms was found; he died on the tenth day. At autopsy an acute osteomyelitis of the second and third dorsal vertebrae with related extradural pus was discovered. The connection between this and the operation was not clear though it seems possible that the vertebral disease was due to an infective venous thrombosis from the site of operation. Up to the end of 1949 a further 118 patients had been operated upon without a death, making a mortality rate of 0.32 per cent for 618 cases.

TABLE XIII

Post-operative Complications

\begin{tabular}{|c|c|c|}
\hline & No. of cases & $\%$ \\
\hline Wound infection . . . & 15 & $3 \cdot 0$ \\
\hline Haematoma formation (superficial) & 10 & $2 \cdot 0$ \\
\hline Pulmonary complications & 5 & $1 \cdot 0$ \\
\hline Retention of urine (12-48 hours) & infrequent & - \\
\hline Post-operative pain in back and groin & 8 & $1 \cdot 6$ \\
\hline
\end{tabular}

\section{COMPLIGATIONS (TABLE XIII)}

Retention of urine was infrequent and catheterisation was required in less than 2 per cent of patients. Attacks of lumbar and inguinal pain occurred in eight cases. They usually developed after the patient had begun to walk; the pain might be severe but was always transient. In three patients small burns were caused in the lower limbs by the plate of the diathermy circuit. In one case there was an increase in the lower limb weakness when the patient began to walk. This patient had well-marked osteoarthritis of the spine, and an extradural nerve was firmly adherent to the disc protrusion; weakness of dorsiflexion and eversion of the ankle was greater after operation. There have been three cases in which sudden weakness of dorsiflexion of the foot occurred several years after operation. In two it persisted for a few days only, but in the third it gave rise to a permanent foot drop necessitating a tendon transplantation. The explanation is not obvious. As the sudden onset of weakness was accompanied in each case by back and leg pains of a few hours' duration it is possible that a sudden displacement of more disc tissue caused the nerve injury. 


\section{RESULTS}

We have already indicated that as the disturbance caused by disc protrusions is essentially subjective the assessment of the results of treatment presents difficulties. The first requisite is, we believe, a knowledge of the individual patient so that a fair comparison of his pre-operative symptoms and signs with his post-operative condition can be made. Secondly, the results of operation must be considered against a background of the indications which led to it. If pain of short duration and low intensity has been accepted as an indication for surgery it is clear that even mild post-operative symptoms denote part or complete failure. On the other hand, if operation has been reserved for patients whose pain has been severe or whose disability has been prolonged, mild post-operative symptoms may be much less important to patient and surgeon. In the present series operation has been confined to patients with severe or prolonged symptoms. Thirdly, to assess adequately the results of treatment a sufficiently large series of cases must be reviewed and they must be observed after operation

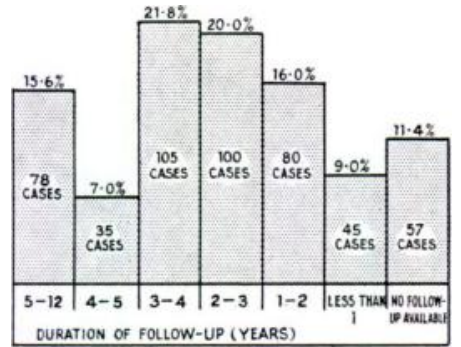

Fig. 22

leriod of post-operative observation in the cases of the series.

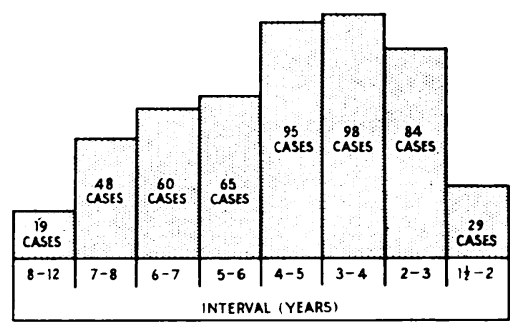

FIG. 23

Time interval since operation in the cases of the series.

for an adequate period. In this series 113 patients were observed for more than four years after operation; 218 patients were observed for more than three years; and 318 patients for more than two years (Figs. 22 and 23).

The results will be considered on the basis of: 1) freedom from lumbar and lower limb pain ; 2) subjective disability ; 3) capacity for work; and 4) objective findings.

Lumbar and lower limb pain. (Table XIV)-In $46 \cdot 5$ per cent of patients there were no symptoms referable to the disc lesion, while in 53.5 per cent some such symptoms were present. Lower limb pain was completely relieved in $77 \cdot 6$ per cent, but $22 \cdot 5$ per cent had some lower limb pain post-operatively. It was persistent in only eight cases $(1.8$ per cent); in the great majority it was slight and transient. Possibly scarring in and around the extradural nerve is at times responsible for this lower limb pain but there is also the possibility of small recurrent protrusions, insufficiently troublesome to warrant re-exploration. Low back pain was completely relieved in 60 per cent of the patients, but 40 per cent had some lumbar pain after operation. In only $6 \cdot 2$ per cent of these was this symptom severe or persistent. In most it was no more than a mild sense of discomfort after exertion.

Subjective disability - The patient's own opinion of the effectiveness of the operation is shown in Table XIV. The term cured implies complete absence of symptoms, apart from pre-menstrual backache or aching in the back or leg with climatic alterations. Much improved implies that the patient was well satisfied with the result but developed backache after heavy exertion or had had one or more transient attacks of acute back pain-sometimes spreading to the leg. If pre-operative muscular weakness was severe some may persist. It will be seen that over 92 per cent of the patients were either cured or much improved. Improved implies persistent or recurring pain in the back or leg, but reduced in severity and not such as to indicate re-operation in search of a recurrent protrusion. The three

vol. 33 B, No. 1, FEBRUARY 1951 
patients unchanged by operation are later referred to as incapacitated and the probable reason for the poor result is indicated.

Capacity for work-On discharge from hospital our patients are advised as far as possible to avoid back strains. (Thus a girl contemplating a career in nursing is counselled against it.) Nevertheless one is usually reluctant to advise a complete change of occupation, with all the financial problems that this implies; caution and the avoidance of avoidable back strain is probably the only advice one can give to most patients. Many have returned to the heaviest

TABLE XIV

Results OF OPERATION

(443 patients followed up)

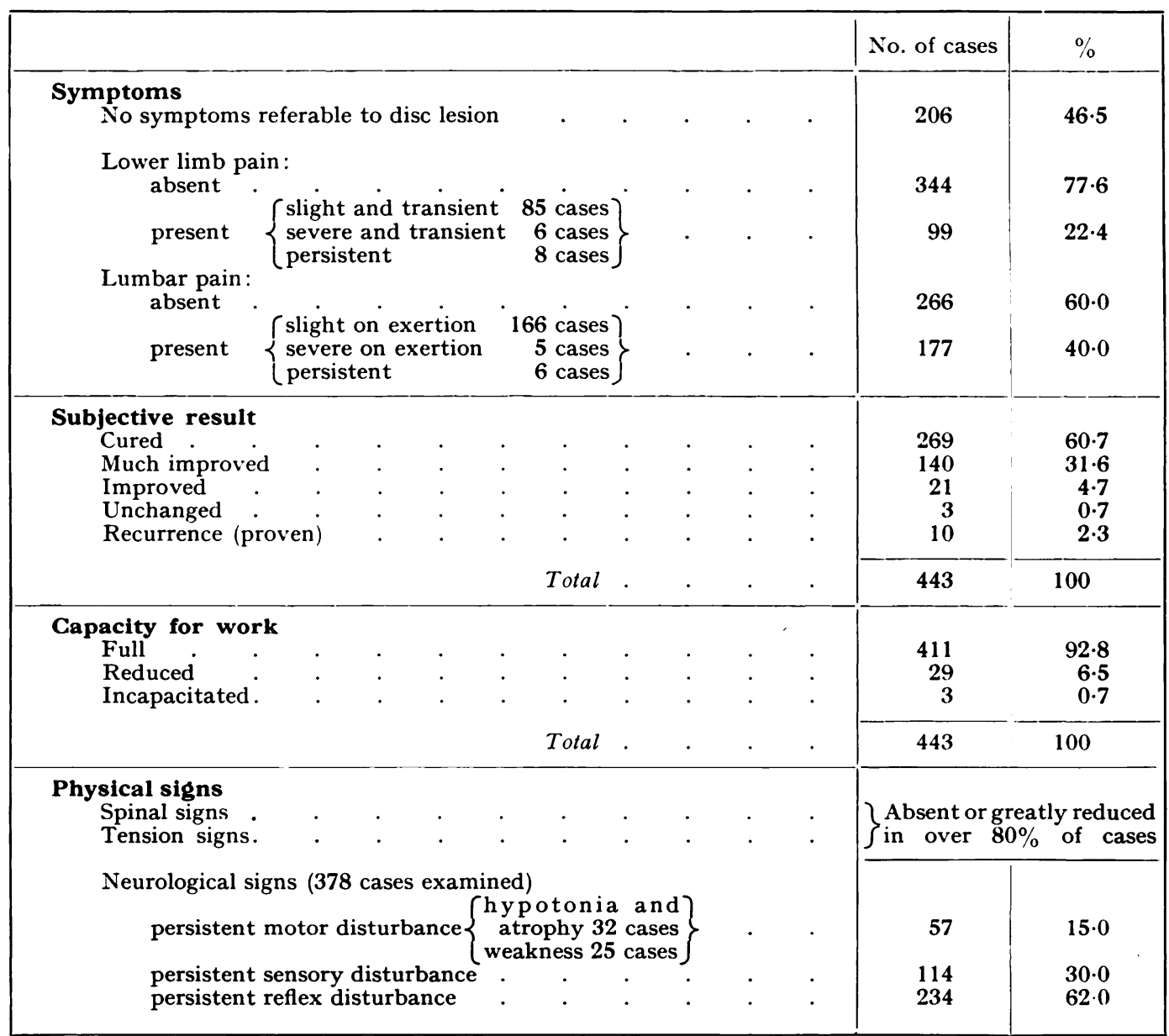

manual labour and others have been able to indulge in strenuous athletic pursuits such as rugby football and hockey. The results from the standpoint of work are shown in Table XIV. As would be expected most patients return to full work. Only three patients remained incapacitated: one because of severe osteoarthritis of the spine and the other two probably because of an overlying neurosis.

Objective findings. (Table XIV)-Of the spinal signs deformity disappears in most cases, except diminution in the lumbar curve, which frequently persists; local tenderness likewise disappears; movement of full range is usually restored though often it seems that full flexion is gained by a compensatory increased movement in the hips and upper lumbar joints-the 
affected region of the spine remaining relatively immobile. The tension signs disappear in most patients: straight leg raising and femoral nerve stretching cause no more than a sense of tightness in the posterior muscles or the quadriceps. Persistent, though usually not significant, neurological disturbance is frequently seen. Reduction or absence of one or more of the tendon reflexes-in particular the ankle jerk-is the commonest abnormality and was seen in over 60 per cent of the cases. An area of reduced cutaneous sensibility was found in 30 per cent. Persistent disturbance of motor function was the least common neurological abnormality: hypotonia with atrophy was seen in 8.5 per cent. The disturbance was usually slight; except in the case of upper lumbar disc protrusions, when the quadriceps was involved, it affected the muscles innervated by the fifth lumbar and upper sacral roots-that is, the glutei, the hamstrings and the muscles below the knee. It is probable that a mild degree of atrophy in the peronei and dorsiflexor muscles of the ankles and toes will frequently pass unnoticed; so also will atrophy of the intrinsic muscles of the foot. Demonstrable muscle weakness was observed in 6.5 per cent of the cases followed up. This may affect any of the muscle groups mentioned above, but the groups most frequently affected were the dorsiflexors of the hallux or lateral toes and, less commonly, the plantar flexors of the toes. Muscles of relatively small mass at the periphery of the limb supplied by the affected anterior root or roots seem especially liable to suffer lasting weakness. Nevertheless the residual weakness was usually very slight. The five patients who developed a severe paraparesis in association with massive disc protrusion gained adequate motor recovery. The rate of recovery appeared to depend upon whether compression or trauma had been responsible for the cauda equina disturbance. In two of these patients severe weakness of dorsiflexion and eversion of one ankle have persisted, and it is noteworthy that there have been a few other patients in the series who complained primarily of an isolated weakness of the same movements. At operation in this latter group a large protrusion particularly related to one extradural nerve was found. Removal of the protrusion was not followed by recovery of motor function in several cases of this group.

The frequent persistence of impairment of tendon reflexes is perhaps explained by the fact that they depend upon the integrity of both motor and sensory fibres. Even when the loss of either type of fibre is insufficient to produce demonstrable motor or sensory disturbance their combined loss may cause reflex disturbance. Moreover the large fibres in the posterior nerve roots which subserve proprioceptive sensibility are the most vulnerable to compression. Reduced cutaneous sensibility is explained thus: an intervertebral disc protrusion injures the posterior nerve root fibres central to their ganglion cells; if this injury is severe enough to cause fibre degeneration, the consequent sensory deficit will be persistent because there is no regeneration of the parts of these root fibres within the spinal canal. It has been noted that paralysis of the dorsiflexors of the ankle and toes and of the evertors of the foot on one side may persist after the removal of a massive central protrusion which caused a cauda equina syndrome. It may also persist after the excision of a large laterally placed protrusion when its effects appeared to be largely confined to the extradural nerve. In each type of case there is almost certainly injury to both the intradural nerve roots and the extradural nerve at the level of the protrusion. Perhaps the tension within the extradural nerve renders it especially vulnerable, and the severe lesion produced in it may play an important part in the causation of the paralysis under discussion.

Recurrent protrusions-The reported frequency of recurrent intervertebral disc protrusions after operation varies among different authors. It must be remembered that only a proportion of patients with persistent or recurrent post-operative pain will be submitted to a second operation. The problem of assessing the severity of the symptoms exists here just as it did before the primary operation, and there will be a natural reluctance to submit the patient to multiple operations. In the present series recurrent symptoms of such severity as to indicate re-operation occurred in ten patients ( 2 per cent). All of them were cured by the second

VOL. 33 B, NO. 1, FEBRUARY 1951 
operation, which usually revealed a recurrent protrusion in the same position as that previously excised. This was not so in three of the ten cases: in one patient a protrusion of the adjacent disc had occurred, and in another a protrusion of the same disc but on the opposite side; in the third patient adhesions only were found, binding the extradural nerve to the scarred posterior longitudinal ligament-division of the adhesions and a posterior rhizotomy relieving the symptoms.

\section{GONGLUSIONS}

1. Excision of a lumbar intervertebral disc protrusion is required in only a small proportion of patients with this lesion.

2. A careful clinical and radiological examination of cases of lumbago and pain in the lower limb provides good evidence not only of the presence of a lumbar intervertebral disc protrusion but also of its anatomical level, size and relationships. Such examination is essential for the selection of the patients requiring surgical treatment.

3. In most of these selected cases, a carefully performed operation designed to relieve the affected nerve fibres from forces which stretch and compress them will give satisfying relief of symptoms. In the series reported, 92 per cent of patients were either completely free from symptoms or very greatly improved after operation.

4. The spinal and tension signs present before operation largely disappeared after it. Persistence of a pre-operative neurological deficit after operation is, however, relatively frequent, though seldom disabling.

5. The incidence of post-operative recurrence of symptoms of such severity as to indicate re-operation in the series was 2 per cent.

I should like to record my indebtedness to all those who have helped me in this work, particularly to Mr Harold Wilson who gave me the opportunity of beginning the work when I was his chief assistant, and to Sir James Paterson Ross who later made its continuation possible. I am indebted to orthopaedic colleagues, Mr S. L. Higgs, Mr H. Jackson Burrows, Mr W. D. Coltart and Mr L. W. Plewes for many of the cases.

\section{REFERENCES}

Mixter, W. J., and Barr, J. S. (1934): New England Journal of Medicine, 211, 210.

O'Connell, J. E. A. (1943): British Journal of Surgery, 30, 315.

O'Connell, J. E. A. (1944): Surgery, Gynecology and Obstetrics, 79, 374.

O'Connell, J. E. A. (1946): British Medical Journal, i, 122. 